\title{
XVII. On the ultimate composition of simple alimentary substances; with some preliminary remarks on the analysis of organized bodies in general
}

William Prout M.D. F.R.S.

To cite this article: William Prout M.D. F.R.S. (1828) XVII. On the ultimate composition of simple alimentary substances; with some preliminary remarks on the analysis of organized bodies in general , Philosophical Magazine Series 2, 3:14, 98-111, DOI: $10.1080 / 14786442808674561$

To link to this article: http://dx.doi.org/10.1080/14786442808674561

曲 Published online: 10 Jul 2009.

Submit your article to this journal $₫$

山l Article views: 2

Q View related articles $\longleftarrow$ 
proof of the correctness of Lagrange's solution that Mr. Herapath employs to establish the truth of his own.

I am, Gentlemen,

Your obedient servant,

4, Pancras-Lane.

F. R. S.

XVII. On the ultimate Composition of simple Alimentary Substances; with some preliminary Remarks on the Analysis of organized Bodies in general. By William Prout, M.D. F.R.S.

[Concluded from page 40.]

\section{Of the Saccharine principle.}

I $\mathbf{N}$ the following observations, the word Sugar, is used in its ordinary acceptation; but the extended sense in which the term saccharine principle is employed, requires a few remarks.

Messrs. Gay Lussac and Thenard were induced to conclude, from their experiments on organized products, that when the hydrogen and oxygen of a substance exist in it in the proportions in which they form water, the substance is neither acid nor alkaline, as in sugar, starch, gum, \&c. ; that when the oxygen exceeds this proportion, the substance possesses acid properties; that when it is less, an oily or resinous character*. These conclusions are true to a certain extent, but by no means universally so, as will be shown hereafter. I shall however adopt this general distribution of organized substances so far, as to confine my attention at present to those substances in which the first peculiarity above mentioned exists ; and as sugar, on account of its crystalline form, appears to constitute the most perfect and definite of these substances, I have thought it best entitled to give a name to the whole class, or family, and hence have included, under the term saccharine principle, all those substances, whatever their sensible properties may be, into the composition of which the hydrogen and oxygen enter in the proportions in which they form water. Now it will be found, that the substances thus constituted may generally be employed as aliments; and as they are chiefly derived from the vegetable kingdom, they may be considered as representing vegetable aliments, properly so called; hence, saccharine principle and vegetable aliment may be regarded as synonymous terms, and they will be so employed throughout the present inquiry.

* Récherches Physico-chimiques, ii. 321. 
As a subject of general interest to chemists, as well as of considerable importance in the present inquiry, I shall also attempt to investigate the composition of a few of the compounds of the saccharine principle with oxygen, or what are usually denominated the vegetable acids.

\section{Of Sugars.}

Many analyses of sugar have been published by different chemists, no two of which agree with each other. These discrepances have doubtless arisen from various causes, though one cause has probably been some real or accidental difference in the composition of the sugars employed*. How many distinct varieties of sugar exist I do not pretend to know, but there are at least two, (independently of the sugar of milk, manna, \&c. which belong to another series,) and probably there are several others; and it is to the mixture or combination of these in different proportions, and the frequent presence of foreign bodies, that a good deal of the confusion respecting the composition of sugar has undoubtedly risen.

Cane Sugar.-The strongest and most perfect sugar that I am acquainted with, is sugar candy carefully prepared from cane sugar. This, purified by repeated crystallizations from water and alcohol, and deprived of the little hygrometric

* Some years ago I published an analysis of sugar, in which the proportions of carbon to water were stated to be to one another as $40: 60$. I was not aware at that time of the differences existing among sugars, and the results given were founded on the analysis of a specimen of remarkably fine looking sugar candy, a quantity of which I had purchased and kept by me for several years for the purposes of experiment ${ }^{2}$. At length my stock became exhausted, and I was surprised to find on analysing other specimens, that they in general contained upwards of one per cent. more of carbon than what $I$ had before examined. This induced me to recur to the notes of my former experiments, but I could detect no material error in them; and though I readily admit that the apparatus I then employed was much less susceptible of accuracy than what I now use, I cannot help thinking that the candy itself was partly in fault, and that it was prepared from an imperfect sugar, probably from the East Indies.

There was also another circumstance which contributed to mislead me, not only in this but in all my other results, viz. an inaccuracy in the weight usually assigned to atmospheric air, at least as regarded my weights. I have long suspected the perfect accuracy of this datum as settled fifty years ago by Sir $G$. Shuckburgh, and have been accustomed for some time past to make an allowance for it; but I was not aware till recently of its exact amount, when I was induced to undertake a series of experiments on the subject, which I hope shortly to lay before the public.

a See Annals of Philosophy, iv. 424 (N.S.) I do not distinctly remember whether, at the time this paper was published, some of the original sugar candy existed or not, but $I$ had then only made one or two experiments on the sugar of commerce. 
moisture that usually adheres to it by exposure for some time to a temperature of $212^{\circ}$, was found to be composed of

$$
\begin{array}{lll}
\text { Carbon ...... } & 42 \cdot 85 \\
\text { Water........ } & 57 \cdot 15
\end{array}
$$

Now, all the finest and purest specimens of loaf sugar of commerce that I have yet examined, give, when similarly treated, precisely the same results. They may therefore be considered as identical in their composition with sugar candy*. Cane sugar appears to undergo no change whatever at the temperature of boiling water; but at about $300^{\circ}$ it begins to melt, and assume the form of a dark-brown liquid. In one experiment, after exposure to this temperature for seven hours, it lost 6 per cent. only of its weight, but its properties seem to have been permanently injured. Berzelius however has shown that, on being combined with lead, sugar parts with about 5.3 per cent. of water without undergoing decomposition; for he has likewise shown that it may be obtained again from the lead in its original state. This saccharate of lead I have several times formed, and once by accident I obtained it iu the state of beautiful crystals.

Sugar of Honey.-The lowest + well-defined sugar that I have yet examined, was first obtained from Narbonne honey, by means of a process formerly pointed out by me for obtaining diabetic sugar in a state of purity $\ddagger$. This, deprived of its hygrometric moisture by being placed under a receiver with sulphuric acid for several days, was found to consist of

$$
\begin{array}{lll}
\text { Carbon ........ } & 36 \cdot 36 \\
\text { Water........ } & 63 \cdot 63
\end{array}
$$

This sugar in the ordinary state of the atmosphere usually contains more water than indicated by this analysis; that is to say, generally about $64 \cdot 7$ per cent. On the other hand, on exposure to a temperature considerably below that of boiling water, it rapidly loses about 3 per cent. of water, and begins to assume the fluid form: kept at the temperature of boiling water for 30 hours, it lost in one experiment upwards

* Dr. Ure states that he has found sugar to contain upwards of 43 per cent. of carbon; but no such specimen has occurred to me, though I by no means deny its existence. Indeed I have hitherto met with no sugar as it occurs in commerce, yielding more than 495 per cent. of carbon, and frequently it contains considerably less than this.

$\dagger$ In commerce, these imperfect sugars are denominated weak or low sugars, which last epithet is here employed in this sense.

$\neq$ Med. Chirurg. Trans. viii. 537. I have little doubt that honey con. tains a still lower sugar, and which is incapable in this country (at least during a great part of the year), of assuming the solid form. This is probably the liquid sugar of Proust. 
of 10 per cent. of its original weight, became of a deep brown colour, and seemed to be partially decomposed *.

Sugar prepared from starch evidently belongs to this variety, as is sufficiently indicated both by its sensible properties and composition. The same is true in general of diabetic sugar, and probably also of the sugar of grapes, figs, \& $c$. When pure, all the varieties of this sugar are beautifully white, crystallize in spherules, and are permanent under the ordinary circumstances of the atmosphere.

Between these two extremes, sugars occur of almost every grade, as the following table will show.

\begin{tabular}{|c|c|c|}
\hline & Carbon. & Water. \\
\hline Pure sugar candy . . . . & $42 \cdot 85$ & $57 \cdot 15$ \\
\hline Impuret sugar candy. & $41 \cdot 5$ to $42 \cdot 5$ & $58 \cdot 5$ to $57 \cdot 5$ \\
\hline East India sugar candy $(v)$ & $4 \cdot 1 \cdot 9$ & $58 \cdot 1$ \\
\hline English refined sugar. . . & $4 \cdot 1 \cdot 5$ to $4.2 \cdot 5$ & $58 \cdot 5$ to $57 \cdot 5$ \\
\hline East India refined sugar $(v)$ & $42 \cdot 2$ & $57 \cdot 8$ \\
\hline Maple sugar $(v) \ldots \ldots$ & $42 \cdot 1$ & $57 \cdot 9$ \\
\hline Beet-root sugar $(v) \ldots$ & $42 \cdot 1$ & $57 \cdot 9$ \\
\hline East India moist sugar $(v)$ & $40 \cdot 88$ & $59 \cdot 12$ \\
\hline Sugar of diabetic urine . & 36 to 40 ? & 64 to $60 ?$ \\
\hline Sugar of Narbonne honey & $36 \cdot 36$ & $63 \cdot 63$ \\
\hline Sugar from starch... & $36 \cdot 2$ & 63.8 \\
\hline
\end{tabular}

On some of these it may be necessary to make a few remarks. The sugar candies of the shops frequently contain minute quantities of foreign fixed bodies, such as lime, \&c., as well as others of a destructible character. Both the specimens of India sugar candy I examined were obviously impure to the eye, being of a brown colour and deliquescent; they contained, among other things, traces of potash. The East India refined sugar was perfectly white, but rather soft and friable, and it did not possess the fine and brilliant grain

* I observed that after this sugar had been cautiously melted it might be preserved in the state of a transparent fluid, if placed in a perfectly dry atmosphere, as under the receiver of an air-pump with sulphuric acid; but that in a few hours after exposure to the air, it began to grow opaque and assume the crystalline form, by attracting moisture. Is not this precisely analogous to the deterioration which is known to take place in the sugars of commerce? See Mr. Daniell on this subject in the Royal Institution Journal, vol. xxxii. Dr. Ure supposes that this deterioration depends on the absorption of oxygen; but I have hitherto met with no sugar containing an excess of oxygen.

$\uparrow$ In these results fixed bodies only have been allowed for, and those marked $(v)$, as occurring in commerce, are probably subject to slight variations in their composition. 
of the best refined sugars of commerce. For a specimen of the maple sugar I was indebted to Mr. Faraday; this, when I received it, was very impure and deliquescent, but by treating it by the process above alluded to, a portion was separated that differed but little in its appearance from cane sugar. The beet-root sugar was made and refined in France; it was perfectly white, but rather soft and fine in the grain. The East India moist sugar was of a very low kind, and known in commerce by the name of Burdwan sugar; it was deprived of its hygrometric moisture before analysis by exposure to sulphuric acid under a receiver. The diabetic sugar was prepared as above; the results given were obtained many years ago, and I have had no opportunity of repeating the analysis with the present apparatus; I believe however that diabetic sugars in general belong to the honey variety. The sugar of starch was prepared by myself in the usual manner.

\section{Of Amylaceous Principles.}

Before we proceed to consider the analysis of amylaceous bodies, a few remarks on the nature of these and similar substances may not be deemed improper. It has been known from the very infancy of chemistry, that all organized bodies, besides the elements of which they are essentially composed, contain minute quantities of different foreign bodies, such as the earthy and alkaline salts, iron, \&c. These have been usually considered as mere mechanical mixtures accidentally present; but I can by no means subscribe to this opinion. Indeed, much attention to this subject for many years past has satisfied me that they perform the most important functions; in short, that organization cannot take place without them. This point will be more fully investigated hereafter : at present it is sufficient merely to observe, that many of those remarkable changes which crystallized bodies undergo on becoming organized, are more apparent than real; that is to say, their chemical composition frequently remains essentially the same; and the only points of difference that can be traced, is the presence of a little more or less of water, or the intimate mixture of a minute portion of some foreign fixed body. There is no term at present employed which expresses this condition of bodies, and hence, to avoid circumlocution, I have provisionally adopted the term merorganized ${ }^{*}$, ( $\mu$ śgos pars vel partim,) meaning to imply by it that bodies on passing into this state become partly, or to a certain extent, organized. Thus starch I consider as merorganized sugar, the two substances having, as we shall see

* I an indebted to my friend Mr. Lunn for this term.

presently; 
presently, the same essential composition, but the starch differing from the sugar by containing minute portions of other matters, which, we may presume, prevent its constituent particles from arranging themselves in the crystalline form, and thus cause it to assume totally different sensible properties*.

Wheat Starch.-The most perfect form of the amylaceous principle is undoubtedly that derived from wheat. 'This has been analysed by different chemists with very different results. MM. Gay Lussac and Thenard state that they found it to contain as much as 43.55 per cent. of carbon; while Dr.Ure informs us that he only found 38.55 per cent. The following observations will sufficiently explain these differences.

A very fine specimen of wheat starch, which had been prepared expressly at my desire without the addition of the colouring matter commonly added to the starch of commerce, and which had been kept in a dry situation for many months, was found, in the ordinary columnar form in which it usually occurs, (abstracting foreign matters, ) to consist of

$$
\begin{array}{lll}
\text { Carbon ....... } & 37 \cdot 5 \\
\text { Water ...... } & 62 \cdot 5
\end{array}
$$

One hundred parts of the same specimen reduced to a state of fine powder, and subjected to a temperature between $200^{\circ}$ and $212^{\circ}$, for the space of twenty hours $f$, lost, in a mean of

* When this subject first occupied my attention many years ago, I was at a loss to form any notion of the modus operandi of these minute admixtures of foreign bodies, except the mechanical one mentioned in the text, viz. that they operated by being inteprposed, as it were, among the essential elements of bodies, and thus by weakening or modifying their natural affinities. But the admirable paper, published by Mr. Herschel, in the Philosophical Transactions for 1824, "On certain motions produced in fiuid conductors when transmitting the electric current," appeared to throw an entire new light on the subject. The facts brought forward in this paper are of the most important kind, and seem to me to be evidently connected with a principle of a more general character, which when completely developed, will lead to the most unexpected results. "That such minute proportions of extraneous matter," says Mr. H. " should be found capable of communicating sensible mechanical motions and properties of a definite character to the body they are mixed with, is perhaps one of the most extraordinary facts that has yet appeared in chemistry. When we see energies so intense exerted by the ordinary forms of matter, we may reasonably ask what evidence we have for the imponderability of any of the powerful agents to which so large a part of the activity of material bodies seem to belong ?"

Any substance may be supposed capable of performing the part of a merorganizing body ; but, in a certain point of view, water appears to constitute the first and chief, at least in organized substances.

II have reasnn to believe from other experiments that six or eight hours, or even less, of steady exposure to the boiling temperature, will sometimes reduce both starch and arrow root, and even gum, to this state of desiccation. 
two experiments, 12.5 parts, and on being analysed in this state gave

$\begin{array}{lll}\text { Carbon ........ } & 42 \cdot 8 \\ \text { Water....... } & 57 \cdot 9\end{array}$

which very nearly coincides with what by calculation it ought to have given, on the supposition that the loss of weight was owing to the escape of water, a circumstance indeed of which there could have been little doubt. Starch however in this state still retains water, a portion of which may be separated by subjecting it to higher temperatures. Thus, after having been exposed as above for twenty-four hours to the temperature of $212^{\circ}$, on being further submitted to a temperature between $300^{\circ}$ and $950^{\circ}$ for six hours longer, it lost 2.3 per cent. more, and analysed in this state gave very nearly

$$
\begin{array}{ll}
\text { Carbon ....... } 44 \\
\text { Water...... } 56
\end{array}
$$

It had now acquired a slight yellow colour, and seemed to have suffered some change in its properties; hence, this is probably nearly the utmost quantity of water that starch is capable of parting with, short of decomposition.

Arrowe root.- This is another variety of the amylaceous principle, of which, like sugar, there seems to be a great variety. The specimen on which the following experiments were made was remarkably fine, and free from adventitious matters. It had been kept in the same drawer with the starch before mentioned, and under precisely similar circumstances of the atmosphere was found to consist of (abstracting foreign matters)

$$
\begin{array}{lll}
\text { Carbon...... } & 36 \cdot 4 \\
\text { Water ...... } & 63 \cdot 6 .
\end{array}
$$

One hundred parts, in the above state, exposed for twenty hours to a temperature between $200^{\circ}$ and $212^{\circ}$, lost fifteen parts. Hence its composition, when thus dried, was very nearly the same as that of wheat starch similarly exsiccated; or it consisted of

Carbon ...... 4.2.8

Water ...... 57\%.

On being subjected to the full temperature of $212^{\circ}$ for six hours longer it lost 3.2 per cent. more, and was then reduced to a state similar to that of starch dried between $300^{\circ}$ and $350^{\circ}$, or it consisted very nearly of

$$
\begin{array}{lll}
\text { Carbon ....... } & 44 \cdot 4 \\
\text { Water....... } & 55 \cdot 6
\end{array}
$$

When subjected to the temperature of $300^{\circ}$ and $350^{\circ}$ for six hours longer, it lost 1.38 per cent. more of its weight, but became of a deeper yellow colour than starch similarly exposed, and consequently showed greater marks of decomposition. Hence, this form of the amylaceous principle, like the sugar of honey before mentioned, seems to part with the whole of 
the water not essential to its composition at the temperature of $212^{\circ}$, or even perhaps below this point if exposed for a period sufficiently long.

It may not be deemed superfluous to notice here very briefly two or three circumstances resulting from the above analyses, which, though their importance may not be seen at present, should be constantly borne in mind, as they will enable us hereafter to throw light on many points connected with organization, which otherwise would be inexplicable.

In the first place, the identity of composition between the sugar of honey and arrow root, under the ordinary circumstances of the atmosphere, seems to show that the differences among the varieties of the amylaceous principles are precisely analogous to those existing among sugars, or in other words, that there are low starches as well as low sugars. Whether arrow root be the lowest that exists, I am unable to say; but I have met with none lower; and have reason to believe that the greater portion of the other varieties of the amylaceous principle known to exist, like the varieties of sugars above given, are intermediate in their composition between arrow root and wheat starch. The same remarks apply to other merorganized principles.

In the second place, the identity of composition between wheat starch and cane sugar, and between the sugar of honey and arrow root above mentioned, seems to show that, though merorganized bodies are not actually capable of assuming the crystalline form, yet that the original tendency among their essential elements to combine in certain proportions (and perhaps to assume certain forms) still continues to operate, though in a mitigated degree, and thus to exert, as it were, a feeble nisus, or endeavour toward the maintenance of certain definite modes of existence.

Thirdly, and lastly, crystallized bodies usually part with their water of crystallation with difficulty, and when they do, it is commonly per saltum, or in definite quantities. Merorganized bodies, on the other hand, retain water so feebly at all points, that within certain limits this fluid may be readily separated, or made to combine with them in every proportion. And this appears to be true, not only with respect to water, but with other substances capable of combining with merorganized bodies. It may be remarked also in general, that low varieties of principles resemble merorganized bodies in these and some other respects; thus, they usually part readily with all the water not essential to their composition at the temperature of $212^{\circ}$, or even less (provided they be submitted to it New Series. Vol. 3. No. 14. Feb. 1828. P long 
long enough,) above which point they rapidly undergo decomposition, \&c.

$$
\text { Lignin, or the Woody Fibre. }
$$

Messrs. Gay Lussac and Thenard first showed that the hydrogen and oxygen in this principle exist in it in the proportions in which they form water, a result fully confirmed by my experiments. The variety of forms in which lignin occurs in different woods is so great, that an examination of them all would be quite out of the question; I therefore selected two, viz. the woods of the Box and Willow, which appeared to present the greatest contrast; the one being among the densest, the other the lightest of the woods. These were both treated exactly in the same manner; that is to say, they were first reduced to the form of a coarse powder by rasping, then well pulverized in a Wedgwood mortar, and afterwards sifted. Being by these means reduced to the form of impalpable powders, they were boiled in repeated portions of distilled water till that fluid came off unchanged: a tedious process, requiring several days to accomplish perfectly. After this they were similarly treated with alcohol, and finally again with distilled water. They were now exposed to the atmosphere, when in a dry and favourable state; and when they ceased to lose weight were submitted to analysis, and found to consist of (abstracting foreign matters)

$$
\begin{array}{lllll} 
& & \text { Box. } & \multicolumn{1}{c}{\text { Willow. }} \\
\text { Carbon } \ldots . . . & 42 \cdot 7 & \ldots \ldots \ldots . . & 42 \cdot 6 \\
\text { Water ....... } & 57 \cdot 3 & \ldots \ldots \ldots . . & 57 \cdot 4
\end{array}
$$

A known weight of each was then exposed for twenty-four hours to a temperature of $212^{\circ}$, and afterwards for six hours longer (by means of an oil bath) to a temperature between $300^{\circ}$ and $350^{\circ}$; and at the end of this time they were found to have lost, per cent.

$$
\begin{array}{cc}
\text { Box. } & \text { Willow. } \\
14 \cdot 6 & 14 \cdot 4
\end{array}
$$

Analysed in this state of desiccation, they were found to consist of Carbon...... $50.0 \quad \ldots . . . . . . . .449 .8$

Water ...... $50 \cdot 0$............ 50.2

showing that the loss of weight arose from the escape of water. These latter results nearly agree with those of MM. Gay Lussac and Thenard, as obtained from the analyses of the woods of the $O a k$ and Beech, and seem to show beyond a doubt, that the composition of all of them is similar, or that they consist of equal weights of carbon and water; to which simple analogy this important principle probably owes its stability.

Lignin undoubtedly exists in many other forms besides the woody 
woody fibre; indeed it appears to constitute the skeleton or ground work on which most organic processes in the vegetable kingdom are carried on. To illustrate its properties as an alinent, the only point of view in which we have to consider it here, I shall briefly quote the experiments of Professor Autenrieth, of Tubingen, who showed some years ago, that by proper management this principle might be rendered capable of forming bread. The following was the method he employed for this purpose. In the first place, every thing that was soluble in water was removed by frequent maceration and boiling. The wood was then reduced to a minute state of division; that is to say, not merely into fine fibres, but actual powder; and after being repeatedly subjected to the heat of an oven, was ground in the usual manner of corn. Wood thus prepared, according to the author, acquires the smell and taste of corn flour. It is however never quite white, but always of a yellowish colour. It also agrees with corn flour in this respect, that it does not ferment without the addition of leaven, and in this case sour leaven of corn flour is found to answer best. With this it makes a perfectly uniform and spongy bread; and when it is thoroughly baked, and has much crust, it has a much better taste of bread than what in times of scarcity is prepared from the bran and husks of corn. Wood flour also, boiled in water, forms a thick tough trembling jelly, like that of wheat starch, and which is very nutritious*.

It may be remarked that all the preceding principles are capable of being converted into oxalic acid by the action of the nitric acid, and into sugar by the action of dilute sulphuric acid.

\section{Acetic Acid, or Vinegar.}

This principle seems to have been more or less used as an aliment, either by accident or design, in every age and country. There have been various analyses of it published, by different chemists; but it is singular, that although some of them have given its exact composition, no one seems to have been struck with the most remarkable peculiarity of its composition + , viz.

* See the Edinburgh Magazine for November 1817, p. 313, where an account is also given of the Lapland mode of making bread from the bark of trees, as described by Von Buch. It is not improbable that during the above processes the lignin combines with watcr, and forms an artificial starch.

+ Berzelins, in his paper On the definite proportions, in which the elements of organic nature are combined, assigns to vinegar this composition. See Aunals of Philosophy, v. 174 (O.S.) Dr. Thomson also, in the last edition of his Chemistry, gives the same composition; though in his more recent work he has assigned to it another proportion of hydrogen. 
that the hydrogen and oxygen exist in it in the proportions in which they form water. Some experiments which I made many years ago appeared to render this probable; but from the difficulties attending the analysis of this acid, and the uncertainty arising from the properties of the oxide of copper formerly stated, I was unable to satisfy myself completely on the subject. On repeatedly burning, however, a very fine specimen of the acetate of copper, in a given bulk of oxygen gas, with the apparatus described at the commencement of this paper, it was found that the volume of the gas underwent no change, and hence, that the above opinion was correct.

Acetic acid, freed from non-essential water, I find to be composed of Carbon ..... 47.05

Water.... 52.95

results which almost exactly agree with those of other chemists.

$$
\text { Sugar of Milk. }
$$

The sugar of milk employed in these experiments was prepared by myself in the usual manner, and rendered as pure as possible by repeated crystallizations. It was then freed from its hygrometric moisture by confinement under a receiver with sulphuric acid, and was found to consist of

$$
\begin{aligned}
& \text { Carbon ... . . 4 } 40 \\
& \text { Water . } 60
\end{aligned}
$$

results almost exactly agreeing with those of Berzelius.

Manna Sugar.-The saccharine principle existing in manna has been long known to possess peculiar properties. That employed in the following analysis was separated by means of alcohol in the manner commonly described in chemical books, and was obtained in a state of perfect purity by repeated crystallizations from that fluid. It was then dried at $212^{\circ}$, and in this state was found to consist of

$$
\begin{aligned}
& \text { Carbon . . . . . 38.7 } \\
& \text { Water . . 61.3 }
\end{aligned}
$$

results very different from those of $M$. Theodore de Saussure*. This sugar seems to part with hygrometric water only at the temperature of boiling water; but a few degrees above this point it begins to suffer decomposition, and at $250^{\circ}$ it assumes, without melting, the form of a brown powder, and acquires a strong empyreumatic odour.

Gum Arabic.-A very fine specimen of gum arabic reduced to powder, and analysed as it existed under the ordinary cir-

* See Bibliothéquc Britannique, 1814; also Annals of Philosophy, vi. 424. 
cumstances of the atmosphere, was found (abstracting foreign matters) to consist of

$$
\begin{aligned}
& \text { Carbon . . . . 36.3 } \\
& \text { Water . . 63.7 }
\end{aligned}
$$

One hundred parts of the same gum, exposed to a temperature between $200^{\circ}$ and $212^{\circ}$, for upwards of twenty hours, lost $12 \cdot 4$ parts. Hence its composition thus dried would be nearly

Carbon .....4.4.4

Water .... 58.6

results confirmed almost exactly by actual analysis.

The same gum, further exposed to a temperature between $300^{\circ}$ and $350^{\circ}$ for six hours longer, assumed a deep brown colour, and seemed to have suffered decomposition, though it lost in weight only $2 \cdot 6$ per cent. more. Hence, gum probably parts with the whole of the water not essential to its composition at the temperature of $212^{\circ}$, provided it be exposed for a sufficient time to this degree of heat.

Substances belonging to this series appear in general to be of a weak or low kind, though they are probably very numerous. They may be readily distinguished by being converted into saclactic acid by the action of nitric acid.

The vegetable Acids.

Oxalic Acid.-Many years ago I ascertained that this acid in the crystallized state consists of

$$
\begin{aligned}
& \text { Carbon . . . . 19.04 } \\
& \text { Water . . . 42.85 } \\
& \text { Oxygen . . . 38.11 }
\end{aligned}
$$

a composition assigned to it long since by other chemists, and now I believe generally admitted, except by Dr. Thomson, who informs us that he has met with a specimen containing as much as half its weight of water*. I have examined a great many specimens with the view of verifying this result, but hitherto have not been successful.

Citric Acid.-This and all the following acids, except the matic, were analysed at the same period as the oxalic acid above mentioned, and the results have been recently verified. I find the crystals of citric acid to consist of

$$
\begin{aligned}
& \text { Carbon . . . . } 34 \cdot 28 \\
& \text { Water . . . } 42 \cdot 85 \\
& \text { Oxygen . . . } 22 \cdot 87
\end{aligned}
$$

This composition has been approached very nearly by several chemists; but no one, so far as I know, has given it exactly.

* Attempt to establish the first principles of chemistry by experiment, ii. 103 . 
Tartaric Acid in crystals is composed of

$$
\begin{aligned}
& \text { Carbon . . . . 32.0 } \\
& \text { Water . . 36.0 } \\
& \text { Oxygen . . 32.0 }
\end{aligned}
$$

a composition assigned to it by Dr. Thomson in his work just quoted.

Malic Acid.-I am not acquainted with any analysis of malic acid except that of M. Vauquelin*, which has not, I believe, obtained much confidence among chemists, chiefly on account of the large proportion of hydrogen which he assigns to it. The acid 1 employed was obtained from the berries of the mountain ash by a process very similar to that of Mr. Donovan. It was not analysed per se, but in combination with lead, with lime, and with copper, and was found, abstracting water not essential to its composition, to consist of

$$
\begin{aligned}
& \text { Carbon . . . . 40.68 } \\
& \text { Water . . } 45 \cdot 76 \\
& \text { Oxygen. . . 13.56 }
\end{aligned}
$$

This acid, in many points of view, may be regarded as one of the most interesting and important of all the vegetable acids.

Saclactic Acid.-The unexpected composition of this acid induced me to investigate its properties more fully than I had otherwise intended. What I first employed was obtained from the sugar of milk, and hence was tolerably pure, though not perhaps completely so. Latterly, I have preferred that prepared from gum, which, though exceedingly impure as first obtained, may be easily and completely purified by the following simple process.

Add ammonia in slight excess to the impure acid, and afterwards as much boiling distilled water as will dissolve the saclactate formed. Filter the solution while boiling hot, and then evaporate it very slowly nearly to dryness. The saclactate of ammonia will be separated in the form of crystals, which are to be washed with cold distilled water till they become quite white and pure. They are now to be again dissolved in distilled water, and the boiling saturated solution permitted to drop from a filter into cold diluted nitric acid. This latter of course decomposes the saclactate, and precipitates the saclactic acid in a state of perfect purity. Thus obtained, this acid was found to consist of

$$
\begin{aligned}
& \text { Carbon ... 33.33 } \\
& \text { Water .... 44.44 } \\
& \text { Oxygen . . 22222 }
\end{aligned}
$$

* Ann. de Chimie et de Physique, tom. vi. 337. 
results differing a little from those of other chemists, who probably did not take the necessary pains to obtain this acid in a perfectly pure state.

In conclusion, I wish to observe, that I purposely abstain at present from making any further observations on the preceding results than those already given. I do this for several reasons: in the first place, such observations will appear with greater effect, when the whole of the facts in my possession are laid before the public; and secondly, I consider that data which lead to such important conclusions as these appear to do, cannot be too firmly established; I therefore, in the mean time, earnestly invite chemists in general to repeat them, and thus either to confirm them, or point out their errors; and for the sake of those who may be inclined to take this trouble, I shall close this part of the subject with the following remarks : 1. The multiples of hydrogen, carbon, and oxygen, are assumed in the preceding calculations as $1: 6: 8$. 2. The results given are, on all essential points, the means of many experiments, the differences among which are either inappreciable, or at most vary from 01 to 03 of a cubic inch in from 5 to 8 cubic inches of carbonic acid or oxygen gas; the greatest differences in general being, for obvious reasons, found among merorganized bodies; and hence the analyses of these are usually stated to the first decimal figure only. 3. As rules to be observed, I would say, that a single result should never be registered, nor a single calculation made, till the operator has made himself complete master of his apparatus, and carefully studied the nature of the substance to be analysed; for different substances often require very different management: that two or three results should never be relied on; the minute quantities here sought can be only obtained, like those of astronomy, by repeated observations: and lastly, the utmost care should be taken that the substances operated on be pure, a point of greater importance, and frequently of more difficult accomplishment than any other, and one that has caused me more trouble than all the rest put together.

XVIII. On the Means of ascertaining the Purity of Sulphate of Quina. By R. PhIllips, F.R.S. L. \& E. \&.c.

THE great demand which has arisen for this important medicine, and the high price at which it is necessarily sold, have excited some, who are careless as to the means by which they acquire gain, to sophisticate it in a vast number of ways, and by every means which talent misapplied could suggest. 